1

Cover Page

2 Endoscopy and Cannulation as Non-Invasive Tools to Identify Sex and Monitor

3 Reproductive Development in Arapaima gigas

4

5 Lucas Simon Torati ${ }^{1,2 *}$, Adriana Ferreira Lima ${ }^{1}$, Luciana Nakaghi Ganeco Kirschnik ${ }^{1}$, and

6 Hervé Migaud $^{2}$

7

$8{ }^{1}$ - EMBRAPA Pesca e Aquicultura, Prolongamento da Av. NS 10, Cruzamento com AV. LO

9 18, Sentido Norte, loteamento Água Fria, CEP 77008-900 Palmas-TO, Brazil. Phone +55 (63) $10 \quad 3229-7800$.

112 - Institute of Aquaculture, University of Stirling, Stirling, FK9 4LA, Scotland, UK. Phone +44 $12 \quad(0) 1786467886$

13

14

15

16

17

18

19

20

21

22

23

24

25

26 
28 The lack of tools for sex identification and assessment of gonadal development are hindering our ability to study the reproductive dysfunction of Arapaima gigas in captivity. This study initially aimed to validate a non-surgical endoscopy procedure to identify sex in juveniles and assess stage of ovary development in female broodstock under field operational conditions. Cannulation, assisted through the description of the genital anatomy, made ovarian biopsy possible to describe oocyte development from primary growth to pre-ovulation, providing a first classification scheme for oogenesis in the species including description of the micropyle morphology using scanning electron microscopy. Cannulation was also successfully performed without endoscopic guidance, which allowed monitoring of the ovarian development along the reproductive season together with profiling of plasma sex steroids $\left(17 \beta\right.$-oestradiol $\left(\mathrm{E}_{2}\right)$ and 11ketotestosterone (11-KT) in females and males respectively). The monitoring of our study population showed females paired with males in earthponds sexually matured and reached oocyte maturation during the spawning season. However, since no spawning was recorded, eggs had either been resorbed or released and not fertilized by the male. Plasma $E_{2}$ levels remained high in females, as expected in an asynchronous species during the spawning season with multiple batches of oocytes being recruited. Plasma 11-KT showed a tendency to decrease suggesting a male reproductive dysfunction or the end of the reproductive season with a lack of synchronisation between genders. In conclusion, endoscopy and cannulation are tools that can be promptly applied to aid sex identification, assessment of reproductive function and overall broodstock management in wild and captive stocks. These tools will greatly help future studies looking at the effects of environmental, social and hormonal cues on reproductive development with the aim to develop a spawning induction protocol for the species. 


\section{Body of text}

The Pirarucu Arapaima gigas is a dioic and iteroparous species without evident sexual dimorphisms (Chu-Koo et al., 2009). Like salmonid and anguillid species, the ovary of A. gigas lacks an external capsule (gymnovarium), meaning mature oocytes are directly released into the coelomatic cavity before reaching the gonopore at spawning (Grier et al., 2009; Godinho et al., 2005; Colombo et al., 1984). However, the gonopore morphology and position have not been described, which hindered the practice of cannulation (Núñez et al., 2011; Chu-Koo et al., 2009). This is a major constraint to the study of reproductive function in the species for both wild and captive stocks (Torati et al., 2016; Núñez et al., 2011), as assessment of reproductive condition can only rely on sacrificing animals to sample gametes, which contrasts with conservation efforts. Consequently, data on gonadal development, oocyte maturation, ovulation, and spawning rhythms is still scarce (Godinho et al., 2005; Núñez and Duponchelle, 2009) as for data on spawning rhythms. These gaps in knowledge have limited greatly progress made over recent years to optimise reproduction of $A$. gigas in captivity.

Arapaima gigas breeding and spontaneous spawning have been reported in captivity in many different farms across South America, however it remains uncontrolled and unpredictable. Empirical evidence suggests that nutrition and rainfall act as proximate factors for the control of final oocyte maturation and spawning (Núñez et al., 2011; Migaud et al., 2010). However, still very little is known about the reproductive dysfunction of A. gigas in captivity. Current practices for breeding the species consist of isolating pairs randomly into earthen ponds without any scientific and validated assessment of sex and/or reproductive condition (Núñez et al., 2011). Available methods to identify gender in A. gigas include color patterns, which display large intra- and interpopulation variability, and can therefore be considered as unreliable (ChuKoo et al., 2009). Other methods to identify sex were investigated using genetic karyotyping and bulked segregant analyses (Rosa et al., 2009; Almeida et al., 2013), however these were not successful (Almeida et al., 2013). Hormonal analyses can be used to identify sex using the ratio between plasma $\mathrm{E}_{2}$ and 11-KT in maturing and also immature individuals, although reliability of the technique may not be guaranteed (Chu-Koo et al., 2009). In addition, a vitellogenin enzyme 
immune assay was developed and can be used to identify adult females (Dugue et al., 2008; Chu-Koo et al., 2009). Alternatively, surgical laparoscopy was used to visualize gonads in juveniles (Carreiro et al., 2011); however, in practice, this method is laborious, not fully reliable, and very invasive with associated welfare concerns.

Recently, a non-surgical endoscopy procedure showed promising results that allowed images to be taken from the ovary of adult female A. gigas (Torati et al., 2016), and the gross inference of stage of ovarian development through the coloration of oocytes. Endoscopy has been carried out recently in a proof-of-concept study on a limited number of adult A. gigas; however, the method required further validation under field operational conditions before it can be implemented into the industry (Torati et al., 2016). In addition, this method only provided empirical observations as samples can not be obtained for further characterization of the oocytes (e.g. diameter, histological analyses) without cannulation. Importantly, although the coelomatic cavity could be visualized through the use of modern endoscopy apparatus, the morphology of the urogenital papillae has not yet been described preventing the use of cannulation. Further work is clearly required to address these limitations.

The aims of the current study were therefore: 1) to validate endoscopy described in Torati et al. (2016) in adult females under field operational conditions and test the method for the first time in juveniles $(\sim 10 \mathrm{~kg})$ as a possible tool for early sex identification and assessment of reproductive development, 2) to describe the anatomy of female urogenital papillae for enabling collection of ovarian biopsy through cannulation and provide a detailed scheme of oogenesis from primary growth to pre-ovulation, and 3) to use oocyte staging associated with sex steroid analysis to monitor the reproductive function of a captive broodstock population.

\section{MATERIALS AND METHODS}

Fish, endoscopy and sampling procedures.-From $20^{\text {th }}$ to $21^{\text {st }}$ Feb 2016, 20 immature juveniles of A. gigas (19 months of age) held in the facilities of Embrapa Fisheries and Aquaculture (Palmas-TO, Brazil), measuring $106.8 \pm 4.6 \mathrm{~cm}$ in total length and weighing $10.2 \pm 1.1 \mathrm{~kg}$ were 
fasted for 24 hours, sacrificed and examined by endoscopy for sex determination and

111 morphological analyses of the urogenital papillae.

Adult broodstock females were studied in a farm located at Taipas-TO $\left(12^{\circ} 09^{\prime} 40.79^{\prime}\right.$ S, 46 51'34.00” W), North Brazil. Broodstock were known to be over six years of age, and reproduction had never been recorded in the study site. Twelve adult females $(n=12$, total length: $166.6 \pm 7.2 \mathrm{~cm}$ and body weight: $43.0 \pm 5.6 \mathrm{~kg})$, and twelve adult males $(\mathrm{n}=12$, total length: $159.6 \pm 9.8 \mathrm{~cm}$, body weight: $37.5 \pm 6.0 \mathrm{~kg}$ ) were monitored. Prior to each sampling, fish were fasted for 24 hours, netted from earthen ponds, and kept contained outside on a soft wet mat for approximately five to 10 minutes. Anaesthetics were not applied during sampling because they have been shown to compromise welfare and resulted in mortalities due to airbreathing behavior of A. gigas (Farrel and Randall, 1978). Fish breathing behavior was closely monitored until they return to normal breathing behavior.

Endoscopy procedures in juvenile and adult fish were performed according to Torati et al. (2016) with the exception of the equipment used in the current study, which was a cistouretroscope $\left(13 \mathrm{~cm} \times 2.6-3.6 \mathrm{~mm}, 6^{\circ}\right.$ of angular field, 8-13.5 Charr operating sheath, model 27030KA, Karl Storz Endoscopy, Tuttlingen, Germany). The main difference with the uretero-renoscope previously used in Torati et al. (2016) is that it is shorter and had better maneuverability. A hydrophilic guidewire (B|Braum, Barcarena-Portugal) was used to inspect the urogenital papilla region and search for the gonopore position (Suppl. video I). The endoscope was equipped with a Telecam camera of 1 chip, a 50 watt Hi-Lux light source and a 15" LCD monitor (200450 01-PT, Tele Pack X, Karl Storz, Tuttlingen, Germany), and all examinations were recorded for later analyses. Ovary visualisation was used to identify juvenile females, and ovary color pattern was observed in adults to estimate overall developmental condition. In sacrificed juveniles, a 4-mm-thick slice was dissected from the gonad median region for histology. In adults, ovary biopsies were taken by inserting a flexible silicon tubing catheter ( $3 \mathrm{~mm}$ internal diameter) into the gonopore and applying a gentle suction using a $25-\mathrm{ml}$ syringe. Collected gonadal samples were fixed in Bouin's solution (Sigma Aldrich, Saint Louis, 
MO, USA) for 24 hours, washed in distilled water and stored in $70 \%$ ethanol until histological analysis.

Broodstock were sampled three times during this study. Initially on $7^{\text {th }}$ Jan 2016 , fish were tagged with a passive integrated transponder (AnimallTAG®, São Carlos, Brazil) inserted in the dorsal muscle to allow individual identification in subsequent samplings. Blood (4 ml maximum) was collected from the caudal vein of males and females using heparinized syringes (BD Precisionglide, New Jersey, USA) flushed with $560 \mathrm{IU} . \mathrm{ml}^{-1}$ heparin ammonium salt solution (Sigma Aldrich, Saint Louis, MO, USA). Blood plasma was extracted after centrifugation at $1200 \mathrm{~g}$ for 15 minutes and stored at $-20{ }^{\circ} \mathrm{C}$ until steroid analysis. Sex was determined with a vitellogenin enzyme immune assay kit (Acobiom, Montpellier, France) developed specifically for A. gigas (Dugue et al., 2008). On $8^{\text {th }}$ Jan 2016, females were randomly paired with males into $250 \mathrm{~m}^{2}$ breeding earthen ponds. By $16^{\text {th }}$ March 2016 , the 12 adult females were examined with endoscopy under practical operational field conditions (Fig. 1A-B), and cannulated to obtain biopsy samples (Fig. 1C). Adult males were not examined under field conditions given prior results obtained for juvenile males showing the spermatic duct can not be reached by endoscopy. On $17^{\text {th }}$ May 2016, the cannulation biopsy procedure was repeated on the same females without endoscopy guidance. No mortalities were recorded following the procedure during the study. using ImageJ v. 1.49 software (Schneider et al., 2012). The oocyte volume was estimated using the formula $\mathrm{V}=1 / 6 \pi \mathrm{OD}^{3}$, where OD is the mean of the oocyte diameters (Jones and Simons, 1983). Measurements made before histological processing aimed to avoid effects of shrinkage and membrane collapsing, which occur after oocyte dehydration in histological protocols (Kennedy et al., 2011). Oocytes analysed for histology ranged in diameter from 354.5 to 2466.0 $\mu \mathrm{m}(\mathrm{n}=363$ oocytes $)$. Samples were gradually dehydrated in ethanol series $(80-90-100 \%)$, 
(Leica Microsystems ${ }^{\mathrm{TM}}$, Wetzlar, Germany). Blocks were sectioned at $3-5 \mu \mathrm{m}$ thick using a rotary microtome (Leica RM 2235, Heidelberg, Germany). Alternatively, oocytes were also infiltered in paraffin, and sectioned in a Shandon Finesse microtome (Thermo Fisher Scientific, Waltham, MA, USA) aiming to improve issues faced with oocyte crumbling during the sectioning step. Slides were stained with hematoxylin - eosin (Fischer et al., 2008) for optical microscopy.

Aiming to provide a detailed characterisation of oocyte development for A. gigas, we adopted the staging terminology from Rhody et al. (2013) and Grier et al. (2018), in which stages are indicated by uppercase letters (i.e. $\mathrm{PG}=$ primary growth), and steps within a stage by lowercase letters (i.e. PGl = late step in primary growth stage). Gonadogenesis stages followed classification of Núñez and Duponchelle (2009). Gonad sections were analyzed using an Olympus BX51 microscope equipped with a Zeiss AxioCam MRc camera system. To describe female reproductive condition, leading cohort oocyte diameter was defined as the mean of the 10 largest oocytes. For juvenile females, the leading cohort was measured from pictures taken after histological sections using the 10 largest oocytes per juvenile female.

Micropyle analysis with scanning electron microscopy.-Given egg release during sampling is not common in A. gigas, non-fertilized eggs could only be kept frozen in liquid $\mathrm{N}_{2}$ instead of being fixed with appropriate fixatives for scanning electron microscopy analysis. Aiming to prevent egg damage during sample thawing, eggs were thawed at room temperature while immersed in a $0.5 \mathrm{M}$ sucrose solution prepared with $\mathrm{NaCl} \mathrm{PBS}$ buffer $(\mathrm{pH} 7.2)$, and then immediately fixed in Karnovsky solution (Karnovsky, 1965) for five hours. Fixed eggs were washed three times for $10 \mathrm{~min}$ in $0.1 \mathrm{M}$ phosphate buffer. A second fixation (2 hours) was made in $1 \%$ osmium tetroxide followed by a quick $(2 \mathrm{sec})$ immersion in distilled water. A gradual dehydration in ethanol was made, increasing $10 \%$ grade until 100\% (15 min each grade). Eggs were dried in a Critical Point K850 (Quorum Technologies, Lewes, UK) following equipment protocol, then carefully mounted onto stubs, coated with gold, and observed in a Zeiss DSM 940A scanning electron microscope. Egg surface was visualized in 20 eggs. Given the 
immovable position of eggs on stubs, a single micropyle was visualized in 5 eggs, and measurements of micropylar cone diameter undertaken in 3 of them.

196

197 Steroid analysis.-Plasma samples were thawed at room temperature, and extraction of sex steroids made mixing $50 \mu 1$ of plasma with $1 \mathrm{ml}$ of ethyl acetate using $1 \mathrm{ml}$ polypropylene assay tubes. The mixture was vigorously vortexed and spun for 1 hour at room temperature $\left(16^{\circ} \mathrm{C}\right)$ using a rotary mixer, then centrifuged at $430 \mathrm{~g}$ for $10 \mathrm{~min}$ at $4^{\circ} \mathrm{C}$. Levels of $\mathrm{E}_{2}$ and $11-\mathrm{KT}$ were quantified in the blood plasma of females and males, respectively, using an enzyme-linked immunosorbent assay (Cayman Chemical Inc., Michigan, USA) previously validated for $A$. gigas (Chu-Koo et al., 2009). Just prior to assay, extracts were dried in a vacuum oven at $35^{\circ} \mathrm{C}$ for 40 minutes. Given sample variability, dilutions in samples ranged from 1:5 to 1:15 (v:v) for 11-KT, and for $\mathrm{E}_{2}$ samples had to be concentrated 6:1 (v:v). The manufacturer's protocol was followed and microplates were read at $405 \mathrm{~nm}$ using a BioEasy microplate reader (Belo Horizonte, Brazil). Steroid concentrations in blood were calculated from the assay value (pg. extraction. Intra-assay coefficients of variation were $6.5 \%$ and $1.7 \%$ for $11-\mathrm{KT}$ for $\mathrm{E}_{2}$, respectively.

Statistics. - Statistical analyses were conducted in Minitab (version 17.3.1, Minitab, PA, USA). One-way repeated measures ANOVA was used to compare steroid levels (ng.ml ${ }^{-1}$ ) during the study period. Paired t-tests were used to compare the leading cohort $(\mathrm{mm})$ for each female between biopsy samplings points ( $16^{\text {th }}$ March and $17^{\text {th }}$ May 2017). The level of significance was set as $\mathrm{P} \leq 0.05$, and values are presented as mean $\pm \mathrm{SE}$.

217

\section{RESULTS}

219 Gonopore position, endoscopy and cannulation in females.-Internally, the ovary was found to be suspended in the coelomatic cavity by the mesovarium, while the intestines and urinary ducts were located dorsaly in relation to the ovary (Fig. 2A-B). Externally, the anus is found 
anteriorly in relation to the urogenital papilla (Fig. 2C). The urogenital papilla is a single opening and no evident sexual dimorphism was found on its external morphology (Fig. 2C). Endoscope insertion, approximately through $4-5 \mathrm{~mm}$ of the female urogenital papilla pore, and using a guiding wire inserted through the endoscope working channel, allowed identification of a membranous septum dividing the gonopore access to the coelomatic cavity, which isventral in relation to the urinary opening (Fig. 2D). The septum recognition was key to visualizing the gonopore and reaching the oviduct and coelomatic cavity where the internal organs and ovary could be visualized (Fig. 2E). In practice, the urinary duct (Fig. 2F) was more easily assessed depending on the angle of insertion if the septum was not noticed or inspected, especially because the septum was normally found collapsed cranially enclosing the gonopore. In juvenile males, neither a septum nor the spermatic duct opening could be observed after endoscopic analyses.

Out of 20 juveniles examined with endoscopy, 11 had the gonopore assessed and left ovary observed after approximately $2.9 \pm 2.7$ minutes of examination. After gonad dissection and histological analyses on sacrificed fish, these were confirmed to be females. Among the remaining 9 fish whose gonopore could not be assessed, 7 were males and 2 were females (Table 1). With this method, male identification remained indirect, and dependent on operator ability to locate the septum to assess the gonopore, and also on fish morphological variability. After histological analyses, the leading cohort in the ovary of juvenile females was classified at the primary growth perinuclear step (PGpn), characteristic of immature fish (Stage I, Table 1). Externally, the ovaries had a pale color and a foliaceous shape when visualized by endoscopy (Fig. 2E).

Field endoscopy in adult females was successfully done without any difficulties (Fig. 1A-B). The coelomatic cavity of 12 adult females was assessed and the ovary observed after approximately $1.24 \pm 1.53$ minutes (Table 2 ). Following endoscopy, a cannula was introduced into the gonopore and oocyte biopsies were sampled (Fig. 1C). With the morphological knowledge gained after endoscopic analyses, cannulation was repeated in the same females two months later without endoscopic guidance. For each biopsy, from 3 to 206 oocytes were 
obtained per individual female (mean of $87.5 \pm 53.4$ ) with a total of 2,101 oocytes staged and measured over the two sampling times. Endoscopy and oocyte analyses combined showed ovaries with a greenish pigmentation at Stage IV with leading cohort oocytes classified either at the germinal vesicle migration stage (OMgvm, $n=10)$ or ovulation $(\mathrm{OV}, \mathrm{n}=1)$. One female had a yellowish ovary at Stage II with leading cohort oocytes at the full-grown stage (SGfg, $n=1$ ) (Suppl. Video I, Table 2).

Oocyte development, Primary growth stage.-Multi-nucleoli oocytes (PGmn) were identified by the presence of several nucleoli scattered within the germinal vesicle. Balbiani bodies were present in the ooplasm, and oocyte diameter ranged from 32.2 to $113.1 \mu \mathrm{m}(72.0 \pm 17.3 \mu \mathrm{m}$; Fig. 3A). Oocytes at the PGmn stepwere present in all juvenile females analyzed, but not in cannulated adults. In all juvenile females studied, the leading oocyte cohort was at the Perinucleoli stage (PGpn). These oocytes were identified by the presence of several spherical nucleoli positioned close to the inner germinal vesicle membrane. Balbiani bodies were still present throughout the ooplasm. The diameter of PGpn oocytes ranged from 64.7 to $320.8 \mu \mathrm{m}$ $(105.2 \pm 103.9 \mu \mathrm{m}$; Fig. 3B). The oil droplet step (PGod) was initiated with the appearance of few oil droplets at the periphery of the ooplasm and cortical alveoli in the ooplam. Cortical alveoli were initiated centripetally with large yolk vesicles deposited in the circumnuclear area. Oocytes at the PGod step were not observed in the juveniles analyzed, and were collected through cannulation of all adult females. In PGod oocytes, the zona pellucida appeared completely formed and visible, and oocyte diameter ranged from 354.5 to $599.0 \mu \mathrm{m}(473.4 \pm$ 82.1 $\mu \mathrm{m}$; Fig. 3C). At the cortical alveoli step (PGca), the multiple layers of cortical alveoli had completely migrated towards the ooplasm periphery. Vesicles of glycoprotein were still present although fewer and smaller compared to the PGod step. The diameter of PGca oocytes ranged from 627.0 to $777.0 \mu \mathrm{m}(697.5 \pm 57.6 \mu \mathrm{m}$; Fig. 3D).

Oocyte development, Secondary growth stage. - The follicle layer was more evident lining the zona pellucida from secondary growth onwards. Early secondary growth (SGe) oocytes were 
distinguished from previous PGca step by a marked increase in the number of small yolk globules (true yolk - lipovitellin and phosvitin) and oil droplets throughout the ooplasm. SGe oocyte diameter ranged from 783.5 to $946.5 \mu \mathrm{m}(892.6 \pm 46.5 \mu \mathrm{m}$; Fig. $4 \mathrm{~A})$. In the late secondary growth (SGI), larger yolk globules became evident surrounding the germinal vesicle. In SGl oocytes, the multiple layers of cortical alveoli became also more compacted lining the zona pellucida, and oocyte diameter ranged from 1007.0 $-1111.5 \mu \mathrm{m}(1066.1 \pm 39.8 \mu \mathrm{m}$; Fig. 4B). In full-grown oocytes (SGfg), an extensive accumulation of oil droplets was observed and these were larger compared to SGl oocytes. Oil droplets were found between the nuclear region and the cortical alveoli layer. At SGfg, oocytes reached their maximum diameter during vitellogenesis ranging from 1139.5 to $1276.0 \mu \mathrm{m}(1214.9 \pm 52.9 \mu \mathrm{m}$; Fig. 4C-D).

Oocyte development, Oocyte maturation and pre-ovulation steps. -The germinal vesicle started its migration towards the animal pole marking the start of the OMgvm stage. During OMgvm, most of the oocyte hydration occurred, at a period when oocytes became greener when observed externally with endoscopy or after biopsy. At this stage, oil droplets started to coalesce becoming larger compared to the SGfg stage, and yolk became more fluid and the nucleocytoplasmic ratio decreased. The diameter of OMgvm oocytes ranged from 1302.5 to 2354.0 $\mu \mathrm{m}(1923.3 \pm 275.6 \mu \mathrm{m}$; Fig. 5A-D). The ovulation (OV) step was observed in one female out of 12, which released eggs during sampling. Ovulated oocytes measured from 2394.0 to 2466.0 $\mu \mathrm{m}(2427.0 \pm 21.4 \mu \mathrm{m})$ in diameter. Ovulated eggs are now surrounded by the chorion since they detached from the follicular layer. In OV oocytes, the germinal vesicle has reached the animal pole and its membrane has broken down (Fig. 6A). Scanning electron microscopy analyses performed on unfertilized OV eggs revealed the presence of a single micropyle in $A$. gigas, which has a series of radially arranged ridges leading into the micropylar canal, whose diameter measured $11.3 \pm 0.02 \mu \mathrm{m}$ (Fig. 6B-C).

Monitoring of the reproductive function of a captive broodstock. -When the 12 couples were first paired in earthponds on $7^{\text {th }}$ January 2016, the cannulation technique had not been developed 
yet. These females were first sampled on $16^{\text {th }}$ March 2016, when 11 of them had their leading cohort oocytes at OMgvm or OV (Table 2, Fig. 7). In comparison with the following sampling undertaken on $17^{\text {th }}$ May 2016, 9 out of these 11 females displayed reduced diameters of their leading cohort oocytes $(\mathrm{P}<0.01$; Fig. 7), revealing ovarian development regressed. The ovary of only a single female ( $(99)$ showed advanced oocyte maturation during the monitoring period (P<0.01; Fig. 7).

Levels of $\mathrm{E}_{2}$ remained steady throughout the rainy season (Fig. 8A, P>0.05), ranging from 0.6 to $16.0 \mathrm{ng} \cdot \mathrm{ml}^{-1}$ (mean of $5.1 \pm 4.5 \mathrm{ng} \cdot \mathrm{ml}^{-1}$ ). In males, levels of $11-\mathrm{KT}$ also remained unchanged with a decreasing trend towards the end of the rainy season (Fig. 8B, P>0.05). It ranged from 4.5 to $59.0 \mathrm{ng} \cdot \mathrm{ml}^{-1}$ (mean of $27.0 \pm 17.2 \mathrm{ng} \cdot \mathrm{ml}^{-1}$ ).

\section{DISCUSSION}

Methods to identify sex and assess fish reproductive development are key to any fish broodstock management program, to understand potential reproductive dysfunctions and validate hormonal therapies (Mylonas et al., 2010; Mylonas et al., 2017). In practice, such methods vary according to the species morphology, ranging from external observations of the abdomen and urogenital papilla intumescence (Carosfeld et al., 2003), biochemical analyses of ovarian fluids (Johnson et al., 2014), cannulation and/or massaging out of oocytes and sperm (Rhody et al., 2013; Martins et al., 2017) or through examinations with ultrasound, endoscopy, boroscopy and laparoscopy instruments (Divers et al., 2009; Wildhaber et al., 2005; Kynard and Kieffe, 2002; Albers et al., 2013; Filho et al., 2016). The description of the urogenital anatomy is essential to perform cannulation and assess gonadal development (Siqueira-Silva et al., 2015; Rasotto and Shapiro, 1998; Carlisle et al., 2000). In A. gigas, there is no evident secondary sexual dimorphism in the urogenital papilla between sexes and cannulation so far has been considered impossible (Chu-Koo et al., 2009). In this study, endoscopy examination in females showed the urinary canal and the gonoduct reach a common aperture inside the urogenital papilla, with their openings separated by a membranous septum. To observe and displace this septum, a guiding wire was used through the endoscope working channel to assess the gonopore 
and observe in situ the ovary. This was made possible both for pre-pubescent (juveniles) and also adult females under farm conditions. Such analyses allowed a rapid and non-invasive validation of the preliminary results described in Torati et al. (2016) with further sex assessment possible in juveniles $(10 \mathrm{~kg})$. New knowledge on the urogenital anatomy was translated into practice through cannulation of adult A. gigas females and oocyte biopsies without endoscopic guidance.

The possibility to monitor reproductive function of $A$. gigas through cannulation was a major breakthrough for the non-invasive study of the species reproduction, and this made it possible to confirm an oocyte development scheme accounting for species-specific variations in oocyte inclusions (i.e. cortical alveoli, oil globules) (Grier, 2012; Grier et al., 2009; Mañanós et al., 2008). Previous studies performed on wild-caught fish have described the early stages of oocyte development in A. gigas from sacrificial samplings (Godinho et al., 2005; Bazzoli and Godinho, 1994) but no cytological details of the final oocyte maturation and ovulation stages were reported, which are key developmental stages to study potential reproductive dysfunctions.

In the present study, a detailed description of oocyte development is presented for $A$. gigas. Transition to oocyte maturation was seen in oocytes from $1.3 \mathrm{~mm}$ onwards, accompanied by a color change from a yellow to greenish pattern due to yolk hydration (Núñez and Duponchelle, 2009; Chu-Koo et al., 2009). At this stage, females are considered capable of spawning and are often selected for hormonal manipulation in hatcheries (Mylonas et al., 2010). Therefore, observation of ovary/oocyte color could be used as a good indicator of final oocyte maturation for field study using either oocyte biopsies or endoscopy. During OM in A. gigas, oocytes increase in diameter from 1.30 to $2.35 \mathrm{~mm}$ (size at pre-ovulation step). This increase is within the typical $1-3$ fold reported for other teleosts due to oocyte hydration (Cerdá et al., 2007). At the pre-ovulation step, eggs have an adhesive gum layer, lack oil globules (which normaly provide buoyancy) and are highly hydrated. These properties help explain their benthic nature when deposited in nests built in shallow areas (Castello, 2008). The present study identified and described for the first time a single micropyle in fully mature eggs from A. gigas. This is a characteristic of most Actinopterygii (Bartsch and Britz, 1997) although not described 
previously for arapaimid species. This information will be useful in future applied investigations on fertilization of A. gigas and comparative biology studies (Isaú et al., 2011) while also supporting current taxonomic debates for Arapaima if biopsies can be obtained from other species (Stewart, 2013b; Stewart, 2013a).

Previous works with wild caught $A$. gigas have reported up to six batches of eggs being recruited and spawned during the reproductive season from October to May, with an interspawning period of approximately 1 month and in some cases, spawning outside the rainy season (Queiroz, 2000). In this study, analyses of ovarian biopsies in A. gigas showed most females had oocytes ranging from primary growth (PGod) to final oocyte maturation (OMgvb), typical of a species with asynchronous ovarian development (Godinho et al., 2005), where several cohorts of developing oocytes subsequently undergo ovulation in successive batches during the spawning season. It has been shown for species with asynchronous ovarian development that plasma $\mathrm{E}_{2}$ levels tend to increase and remain high during the spawning season (Rinchard et al., 1993; Barcellos et al., 2001), when multiple oocyte batches are recruited successively for final oocyte maturation, resulting in batch spawning. Likewise in this study, levels of $\mathrm{E}_{2}$ were found constantly high $\left(c c .5 \mathrm{ng} \cdot \mathrm{ml}^{-1}\right)$ during the monitoring period if compared to previous levels reported for A. gigas outside the reproductive period (Monteiro et al., 2010).

Regarding the possible reproductive dysfunction in A. gigas reared in captivity, this study for the first time demonstrated that females kept with a single male in earthen ponds undergo final oocyte maturation, meaning that they have been recruited into a reproductive cycle. Dysfunction leading to the lack of apparent spawning is due to a failure at the ovulation stage (females) or a lack of spawning synchronization between sexes. For females, the leading cohort of oocytes seen at March $16^{\text {th }}-2016$ was either released and not fertilized in the nests or resorbed in the ovary since at May $17^{\text {th }}-2016$ most of the screened females showed signs of atresia. For males, it is not possible to apply endoscopy and cannulation given the gauge and unknown position of the spermiduct opening, and further studies are therefore required. For this reason, steroid analyses are still key to infer reproductive condition. Our results on levels of 11KT in males showed a tendency to decrease (approx. 2 folds) from $7^{\text {th }}$ Jan -2016 to $17^{\text {th }}$ May - 
2016, suggesting males were reaching the end of the spawning season (start of the drought period in North Brazil). Follow up studies should monitor reproductive function over a longer timeframe and with a higher time resolution to better describe oocyte recruitment, spermatogenesis and spawning rhythms in A. gigas while developing non-invasive methods to monitor male spermatogenesis.

In conclusion, this study advanced our knowledge of the reproductive biology of $A$. gigas in captivity, with novel data on gonad anatomy and ovarian development. With the information provided herein, endoscopy and cannulation are clearly useful tools that can be promptly applied for sex identification and monitoring of reproductive function in wild and captive stocks. As such, the deployment of these tools should help to better understand the environmental, social and hormonal cues that are required to promote or induce spawning in this commercially valuable species. In addition, while no spawning and/or mating could be clearly observed, in all females under investigation, oocytes obtained by biopsy were at final oocyte maturation or ovulation stages. This confirmed that the difficulty to breed A. gigas is not due to reproductive dysfunctions in females during oogenesis but rather at spawning, either due to atresia post-ovulation (lack of spawning), males not spermiating, or a lack of synchronization between sexes. Further testing and optimisation of hormonal therapies should be done to promote spawning in A. gigas together with investigations into male reproductive development and behavior. Finally, the study showed eggs of A. gigas have a single micropyle, whose morphology was described for the first time in an arapaimid species, which could prove useful not only for systematic/taxonomic purposes, but also for potential future studies on fertilisation processes in basal teleost species.

412

DATA ACCESSIBILITY

Supplemental information is available at https://www.copeiajournal.org/XXX. 
417 Authors thank Karl Storz, Strattner and Ana Paula Varges for providing the endoscopy system 418 used, and Celli Muniz and Laura Satiko Okada Nakaghi for scanning electron microscopy 419 analyses performed on eggs of Arapaima. This research complied with the "Brazilian guidelines 420 for the care and use of animals for scientific and educational purposes"-DBCA being approved 421 by the Ethics Committee for the Use of Animals - CEUA of the National Research Center on 422 Fisheries, Aquaculture and Agricultural Systems-CNPASA (specific protocol n09). It has 423 also been approved by the National System for the Management of Genetic Heritage and 424 Associated Traditional Knowledge - SISGen (AA4F2B0).

425

426

427

428

429

430

431

432

433

434

435

436

437

438

439 


\section{LITERATURE CITED}

Albers, J. L., M. L. Wildhaber, and A. J. Delonay. 2013. Gonadosomatic index and fecundity of lower missouri and middle Mississippi River endangered pallid sturgeon estimated using minimally invasive techniques. Journal of Applied Ichthyology 29:968-977.

Almeida, I. G., P. Ianella, M. T. Faria, S. R. Paiva, and A. R. Caetano. 2013. Bulked segregant analysis of the pirarucu (Arapaima gigas) genome for identification of sexspecific molecular markers. Genetics and Molecular Research 12:6299-6308.

Barcellos, L. J., G. F. Wassermann, A. P. Scott, V. M. Woehl, R. M. Quevedo, I. Ittzes, M. H. Krieger, and F. Lulhier. 2001. Steroid profiles in cultured female jundia, the Siluridae Rhamdia quelen (Quoy and Gaimard, Pisces Teleostei), during the first reproductive cycle. General and Comparative Endocrinology 121:325-32.

Bartsch, P., and R. Britz. 1997. A single micropyle in the eggs of the most basal living actinopterygian fish, Polypterus (Actinopterygii, Polypteriformes). Journal of Zoology, London 241:589-592.

Bazzoli, N., and H. P. Godinho. 1994. Cortical alveoli in oocytes of freshwater neotropical teleost fish. Bolletino di Zoologia 61:301-308.

Carlisle, S. L., S. Marxer-Miller, K., A. V. M. Canario, R. F. Oliveira, L. Carneiro, and M. S. Grober. 2000. Effects of 11-ketotestosterone on genital papilla morphology in the sex changing fish Lythrypnus dalli. Journal of Fish Biology 57:445-456.

Carosfeld, J., H. P. Godinho, E. Zaniboni Filho, and B. J. Harvey. 2003. Cryopreservation of sperm in Brazilian migratory fish conservation. Journal of Fish Biology 63:472-489.

Carreiro, C. R. P., M. a. A. Furtado-Neto, P. E. C. Mesquita, and T. A. Bezerra. 2011. Sex determination in the Giant fish of Amazon Basin, Arapaima gigas (Osteoglossiformes, Arapaimatidae), using laparoscopy. Acta Amazonica 41:415-420.

Castello, L. 2008. Nesting habitat of Arapaima gigas (Schinz) in Amazonian floodplains. Journal of Fish Biology 72:1520-1528.

Cerdá, J., M. Fabra, and D. Raldúa. 2007. Physiological and molecular basis of fish oocyte hydration, p. 349-396. In: The fish oocyte: From basic studies to biotechnological 
applications. P. J. Babin, J. Cerdá, and E. Lubzens (eds.) Springer, Dordrecht, Netherlands.

Chu-Koo, F., R. Dugue, M. Alvan Aguilar, A. Casanova Daza, F. Alcantara Bocanegra, C. Chavez Veintemilla, F. Duponchelle, J. F. Renno, S. Tello, and J. Nunez. 2009. Gender determination in the Paiche or Pirarucu (Arapaima gigas) using plasma vitellogenin, 17ß-estradiol, and 11-ketotestosterone levels. Fish Physiology and Biochemistry 35:125-36.

Colombo, G., G. Grandi, and R. Rossi. 1984. Gonad differentiation and body growth in Anguilla anguilla L. Journal of Fish Biology 24:215-228.

Divers, S. J., S. S. Boone, J. J. Hoover, K. A. Boysen, K. J. Killgore, C. E. Murphy, S. G. George, and A. C. Camus. 2009. Field endoscopy for identifying gender, reproductive stage and gonadal anomalies in free-ranging sturgeon (Scaphirhynchus) from the lower Mississippi River. Journal of Applied Ichthyology 25:68-74.

Dugue, R., F. Chu Koo, F. Alcantara, F. Duponchelle, J. F. Renno, and J. Nunez. 2008. Purification and assay of Arapaima gigas vitellogenin: potential use for sex determination. Cybium 32:111-111.

Farrel, A. P., and D. J. Randall. 1978. Air-breathing mechanics in two Amazonian teleosts, Arapaima gigas and Hoplerythrinus unitaeniatus. Canadian Journal of Zoology 56:939945.

Filho, R. M., V. A. Gheller, G. V. Chaves, W. S. Silva, D. C. Costa, L. G. Figueiredo, G. S. C. Julio, and R. K. Luz. 2016. Early sexing techniques in Lophiosilurus alexandri (Steindachner, 1876), a freshwater carnivorous catfish. Theriogenology 86 86:15231529.

Fischer, A. H., K. A. Jacobson, J. Rose, and R. Zeller. 2008. Hematoxylin and eosin staining of tissue and cell sections. Cold Spring Harbor Protocols 3:1-2.

Godinho, H. P., J. E. Santos, P. S. Formagio, and R. J. Guimarães-Cruz. 2005. Gonadal morphology and reproductive traits of the Amazonian fish Arapaima gigas (Schinz, 1822). Acta Zoologica, Stockolm 86:289-294. 
Grier, H. J. 2012. Development of the follicle complex and oocyte staging in Red Drum, Sciaenops ocellatus Linnaeus, 1776 (Perciformes, Sciaenidae). Journal of Morphology 273:801-829.

Grier, H. J., M. C. U. Aranzábal, and R. Patiño. 2009. The ovary, folliculogenesis, and oogenesis in teleosts, p. 24-85. In: Reproductive biology and phylogeny of fishes (Agnathans and Bony Fishes). B. G. M. Jamieson (ed.) Science Publishers, Enfield, New Hampshire.

Grier, H. J., W. F. Porak, J. Carroll, and L. R. Parenti. 2018. Oocyte development and staging in the florida bass, Micropterus floridanus (Lesueur, 1822), with comments on the evolution of pelagic and demersal eggs in bony fishes. Copeia 106:329-345.

Isaú, Z. A., E. Rizzo, and T. B. Amaral. 2011. Structural analysis of oocytes, post-fertilization events and embryonic development of the Brazilian endangered teleost Brycon insignis (Characiformes). Zygote 21:85-94.

Johnson, S. L., M. Villarroel, P. Rosengrave, A. Carne, T. Kleffmann, M. Lokman, and N. J. Gemmell. 2014. Proteomic Analysis of Chinook Salmon (Oncorhynchus tshawytscha) Ovarian Fluid. PloS One 9:e104155.

Jones, M. B., and M. J. Simons. 1983. Latitudinal variation in reproductive characteristics of a mud crab, Helice crassa (Grapsidae). Bulletin of Marine Science 33:656-670.

Karnovsky, M. J. 1965. A formaldehyde-glutaraldehyde fixative of high osmolarity for use in eléctron microscopy. Journal of Cell Biology 27:137-138A.

Kennedy, J., A. C. Gundersen, A. S. Høines, and O. S. Kjesbu. 2011. Greenland halibut (Reinhardtius hippoglossoides) spawn annually but successive cohorts of oocytes develop over 2 years, complicating correct assessment of maturity. Canadian Journal of Fisheries and Aquatic Sciences 68:201-209.

Kynard, B., and M. Kieffe. 2002. Use of a borescope to determine the sex and egg maturity stage of sturgeons and the effect of borescope use on reproductive structures. Journal of Applied Ichthyology 18:505-508. 
Mañanós, E., N. Duncan, and C. C. Mylonas. 2008. Reproduction and control of ovulation, spermiation and spawning in cultured fish. In: Methods in Reproductive Aquaculture: Marine and Freshwater Species. E. Cabrita, V. Robles, and M. P. Herráez (eds.) Taylor and Francis Group CRC Press.

Martins, E. F. F., D. P. Streit, Jr., J. S. Abreu, R. a. C. Correa-Filho, C. a. L. Oliveira, N. M. Lopera-Barrero, and J. A. Povh. 2017. Ovopel and carp pituitary extract for the reproductive induction of Colossoma macropomum males. Theriogenology 98:57-61.

Migaud, H., A. Davie, and J. F. Taylor. 2010. Current knowledge on the photoneuroendocrine regulation of reproduction in temperate fish species. Journal of Fish Biology 76:27-68.

Monteiro, L. B. B., M. C. F. Soares, M. T. J. Catanho, and A. Honczaryk. 2010. Reproductive aspects and sexual steroids hormonal profiles of Pirarucu, Arapaima gigas (Schinz,1822), in captivity conditions. Acta Amazonica 40:435-450.

Mylonas, C. C., N. J. Duncan, and J. F. Asturiano. 2017. Hormonal manipulations for the enhancement of spermproduction in cultured fish and evaluation of sperm quality. Aquaculture 472:21-44.

Mylonas, C. C., A. Fostier, and S. Zanuy. 2010. Broodstock management and hormonal manipulations of fish reproduction. General and Comparative Endocrinology 165:516534.

Núñez, J., F. Chu-Koo, M. Berland, L. Arévalo, O. Ribeyro, F. Duponchelle, and J. Renno. 2011. Reproductive success and fry production of the paiche or pirarucu, Arapaima gigas (Schinz), in the region of Iquitos, Perú. Aquaculture Research 42:815-822.

Núñez, J., and F. Duponchelle. 2009. Towards a universal scale to assess sexual maturation and related life history traits in oviparous teleost fishes. Fish Physiology and Biochemistry 35:167-80.

Queiroz, H. L. 2000. Natural history and conservation of Pirarucu, Arapaima gigas, at the Amazonian Várzea: Red giants in muddy waters. Unpubl. Ph.D. diss., University of St Andrews, St Andrews, Scotland. 
Rasotto, M. B., and D. Y. Shapiro. 1998. Morphology of gonoducts and male genital papilla, in the bluehead wrasse: implications and correlates on the control of gamete release. Journal of Fish Biology 52:716-725.

Rhody, N. R., C. L. Neidig, H. J. Grier, K. L. Main, and H. Migaud. 2013. Assessing reproductive condition in captive and wild Common Snook stocks: A comparison between the wet mount technique and histological preparations. Transactions of the American Fisheries Society 142:979-988.

Rinchard, J., P. Kestemont, E. R. Kühn, and A. Fostier. 1993. Seasonal changes in plasma levels of steroid hormones in an asynchronous fish the Gudgeon Gobio gobio L. (Teleostei: Cyprinidae). General and Comparative Endocrinology 92:168-178.

Schneider, C. A., W. S. Rasband, and K. W. Eliceiri. 2012. NIH Image to ImageJ: 25 years of image analysis. Nature Methods 9:671-675.

Siqueira-Silva, D. H., A. Ninhaus-Silveira, A. P. S. Silva, and R. Veríssimo-Silveira. 2015. Morphology of the urogenital papilla and its component ducts in Astyanax altiparanae Garutti \& Britski, 2000 (Characiformes: Characidae). Neotropical Ichthyology 13:309316.

Stewart, D. J. 2013a. A new species of Arapaima (Osteoglossomorpha: Osteoglossidae) from the Solimões River, Amazonas state, Brazil. Copeia 2013:470-476.

- 2013b. Re-description of Arapaima agassizii (Valenciennes), a rare fish from Brazil (Osteoglossomorpha: Osteoglossidae). Copeia 2013:38-51.

Torati, L. S., A. P. S. Varges, J. a. S. Galvão, P. E. C. Mesquita, and H. Migaud. 2016. Endoscopy application in broodstock management of Arapaima gigas (Schinz, 1822). Journal of Applied Ichthyology 32:353-355.

Wildhaber, M. L., D. M. Papoulias, A. J. Delonay, D. E. Tillitt, J. L. Bryan, M. L. Annis, and J. A. Allert. 2005. Gender identification of shovelnose sturgeon using ultrasonic and endoscopic imagery and the application of the method to the pallid sturgeon. Journal of Fish Biology 67:114-132. 


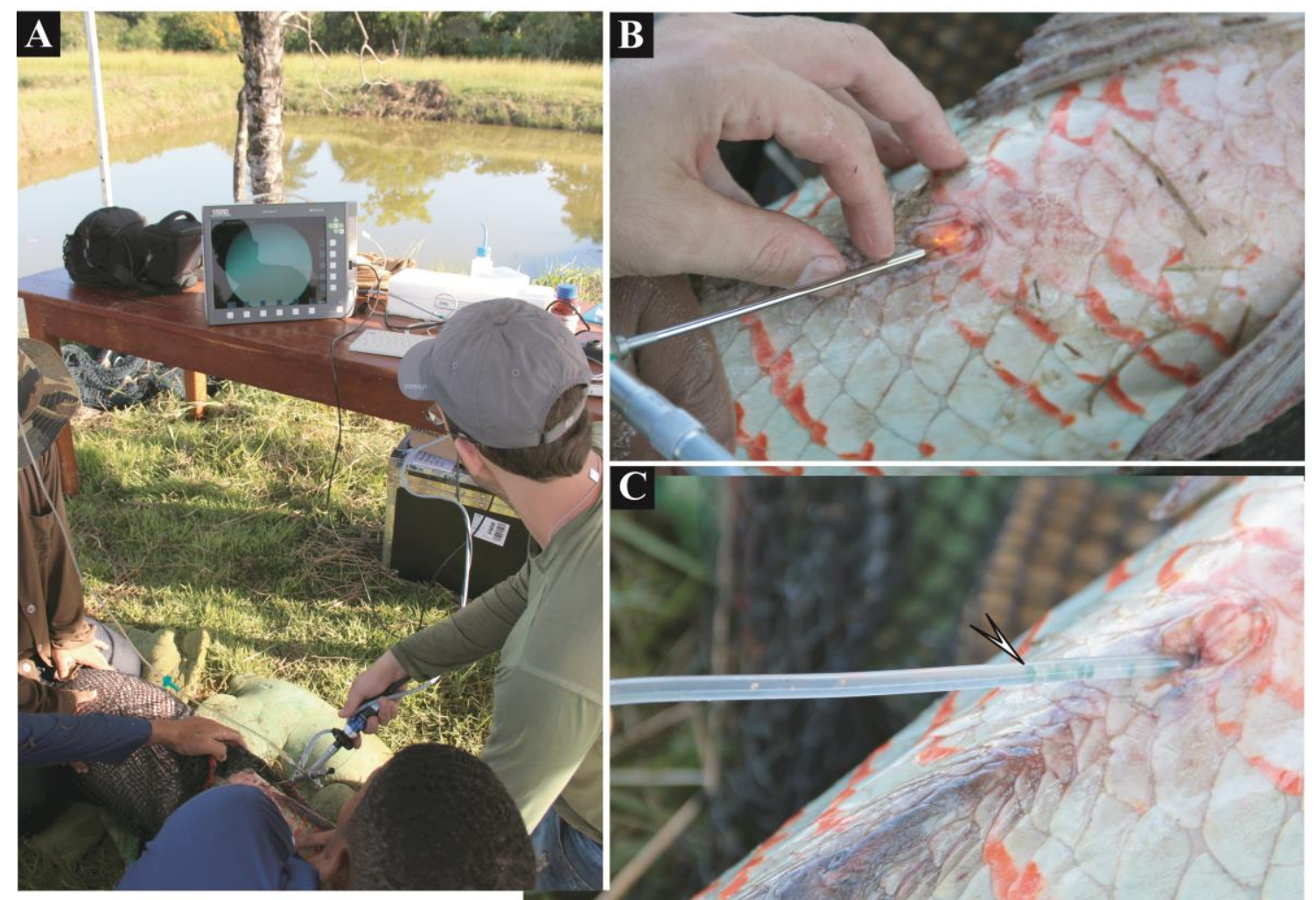

Figure 1. (A) Details of field endoscopy procedure in adult females of Arapaima gigas. (B)

580 Detail of angulation used to access the gonopore and coelomatic cavity during field endoscopy

581 procedure, which allowed observation of the ovary. (C) Detail of a flexible silicon cannula

582 inserted through the gonopore into the coelomatic cavity, suctioning greenish oocytes (arrow). 


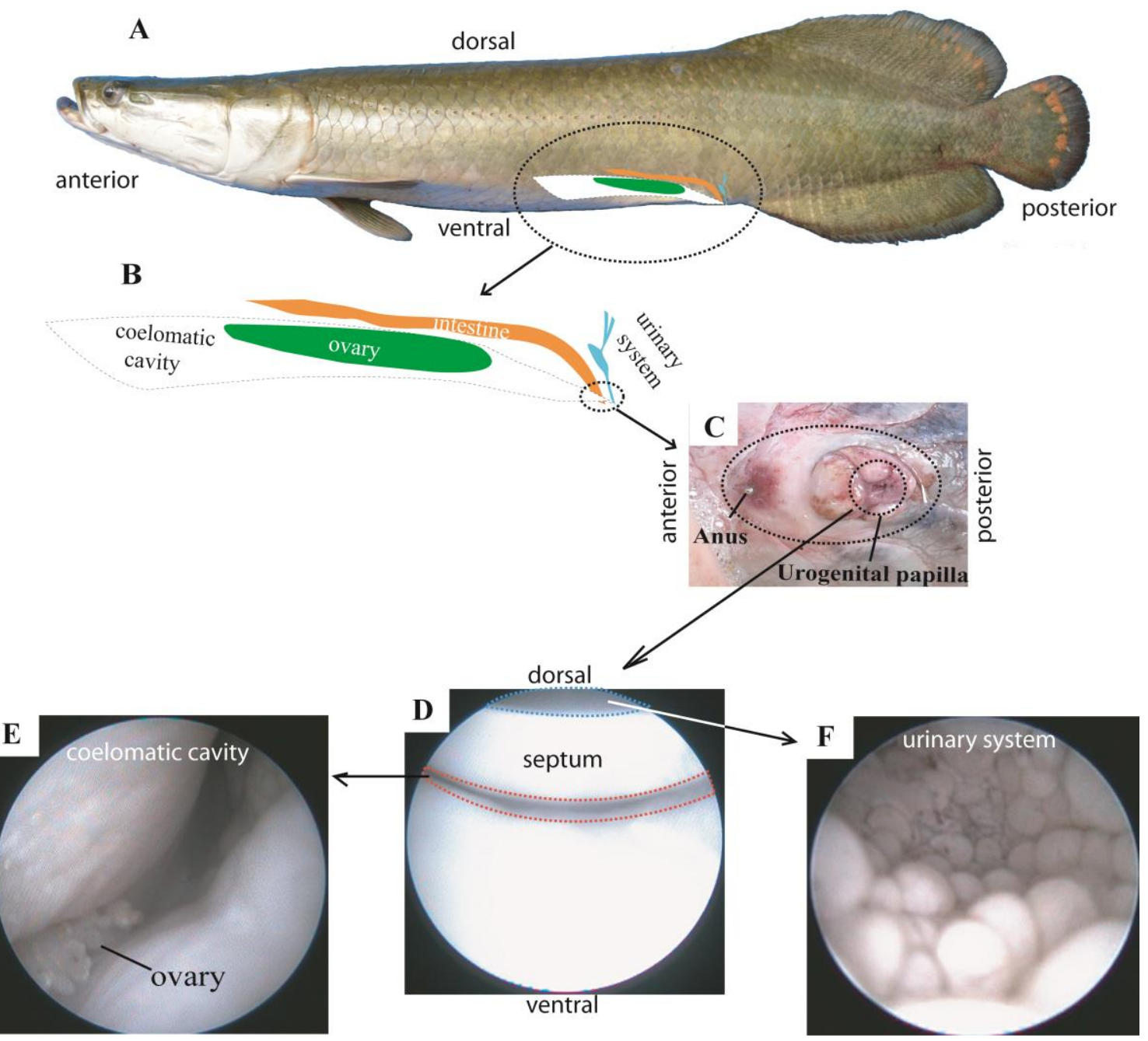

Figure 2. (A) Lateral view of juvenile Arapaima gigas depicting the coelomatic cavity (white),

left ovary (green), intestine (orange) and urinary system (blue). (B) Amplification of coelomatic area where the left ovary lies (green), including relative position of the intestine and urinary system. (C) Picture depicting the relative position of the anus (anterior) in relation to the urogenital papilla (posterior). D. Endoscopic image at the opening (aprox. $0.5 \mathrm{~cm}$ ) of the urogenital papilla depicting the septum (*) which separates the paths into the coelomic cavity (ventral; red-dashed) or the urinary system (dorsal, blue-dashed). (E) Endoscopic image of the coelomatic cavity showing the pale-colored-ovary of a juvenile immature female. (F) Endoscopic image depicting the internal appearance of the urinary bladder.

602 

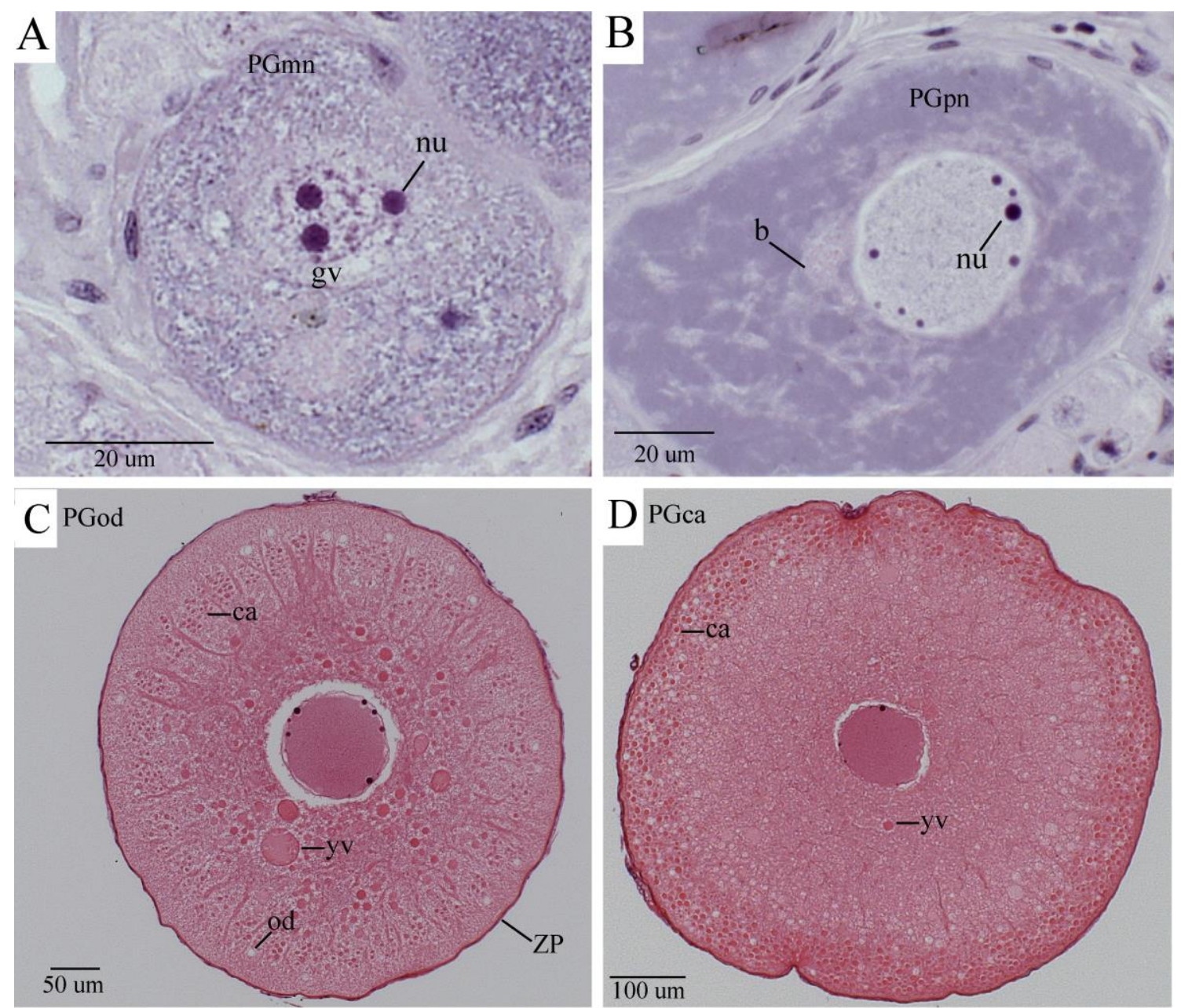

Figure 3. Light micrographs of primary growth (PG) step in oocytes of Arapaima gigas. (A)

607 Multiple nucleoli stage (PGmn), depicting several nucleoli inside the germinal vesicle.

608 Hematoxylin - eosin, Bar=20 $\mu \mathrm{m}$. (B) Perinucleoli (PGpn) stage, nucleoli at the internal margins of the germinal vesicle and Balbiani bodies scattered throughout the ooplasm. Hematoxylin -

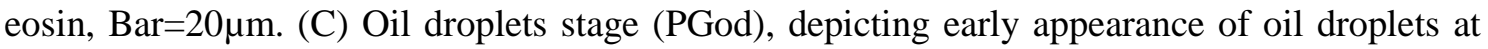

611 the ooplasm periphery, large vesicles of glycoprotein yolk and cortical alveoli. Hematoxylin -

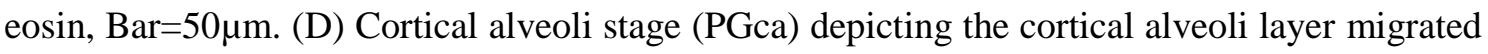
towards ooplasm periphery and yolk vecicles. Hematoxylin - eosin, Bar=100 $\mu \mathrm{m} . \mathrm{b}=$ Balbiani body, $\mathrm{gv}=$ germinal vesicle, $\mathrm{nu}=$ nucleoli, $\mathrm{ca}=$ cortical alveoli, od $=$ oil droplet, $\mathrm{yv}=$ yolk vesicle, $\mathrm{ZP}=$ zona pellucida. 

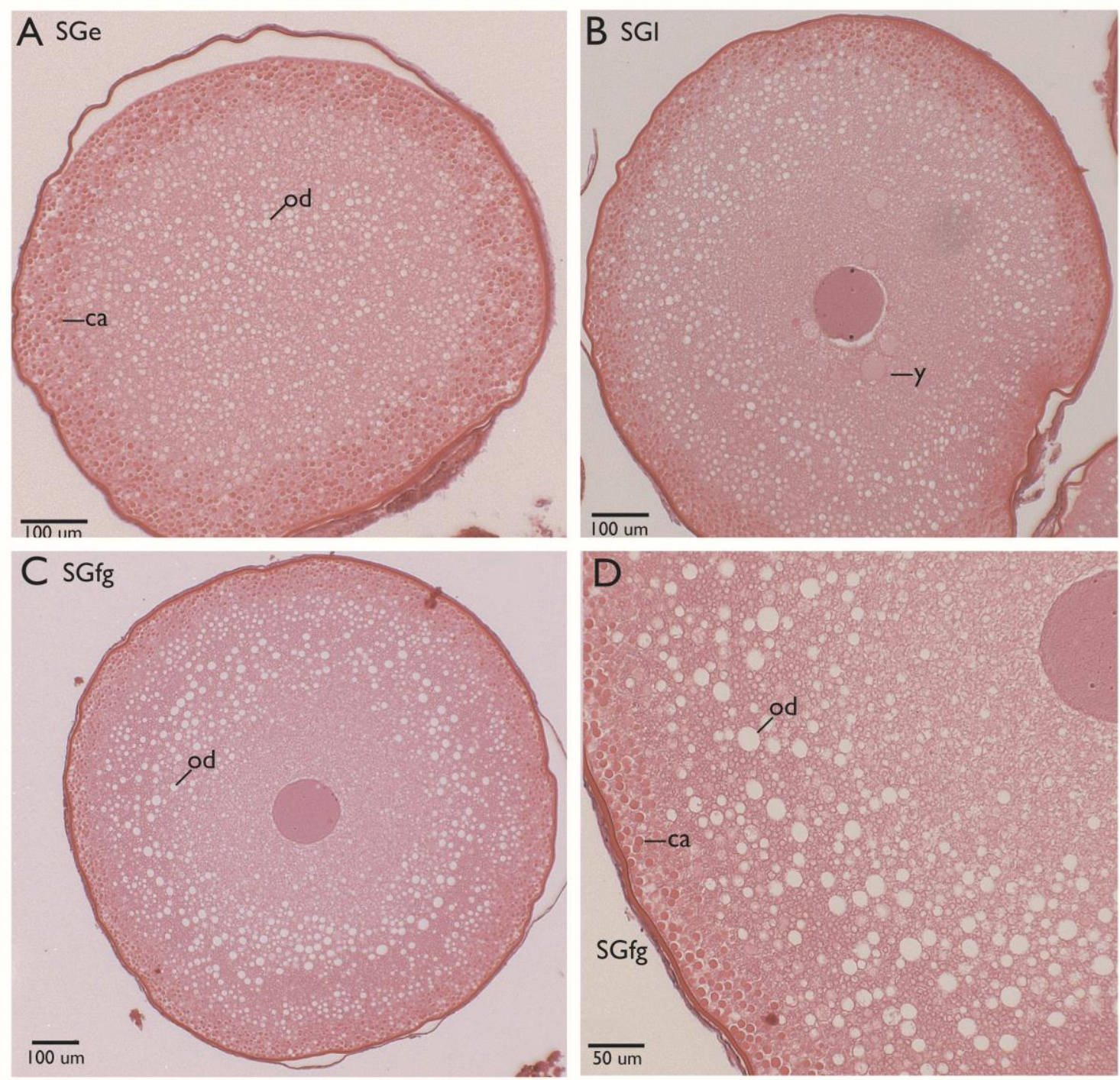

619 Figure 4. Light micrographs of secondary growth (SG) step in Arapaima gigas. (A) Early secondary growth (SGe) depicting wide layer of cortical alveoli at the ooplasm periphery and

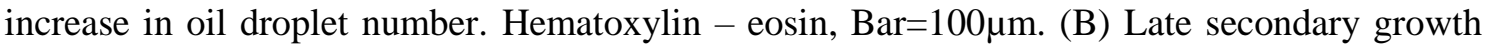
(SGl) depicting appearance of (true) yolk globules at the central region. Hematoxylin - eosin, Bar=100 $\mu \mathrm{m}$. (C) Full-grown (SGfg) oocyte depicting enlarged oil droplets and a thin layer of

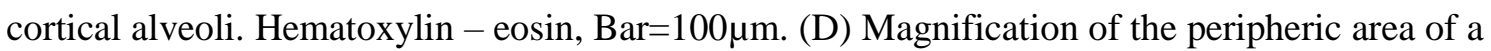
SGfg oocyte depicting the thin layer of cortical alveoli and appearance of oil droplets. Hematoxylin - eosin, Bar=20 $\mu \mathrm{m} . \mathrm{ca}=$ cortical alveoli, od $=$ oil droplet, $\mathrm{y}=$ yolk globules. 

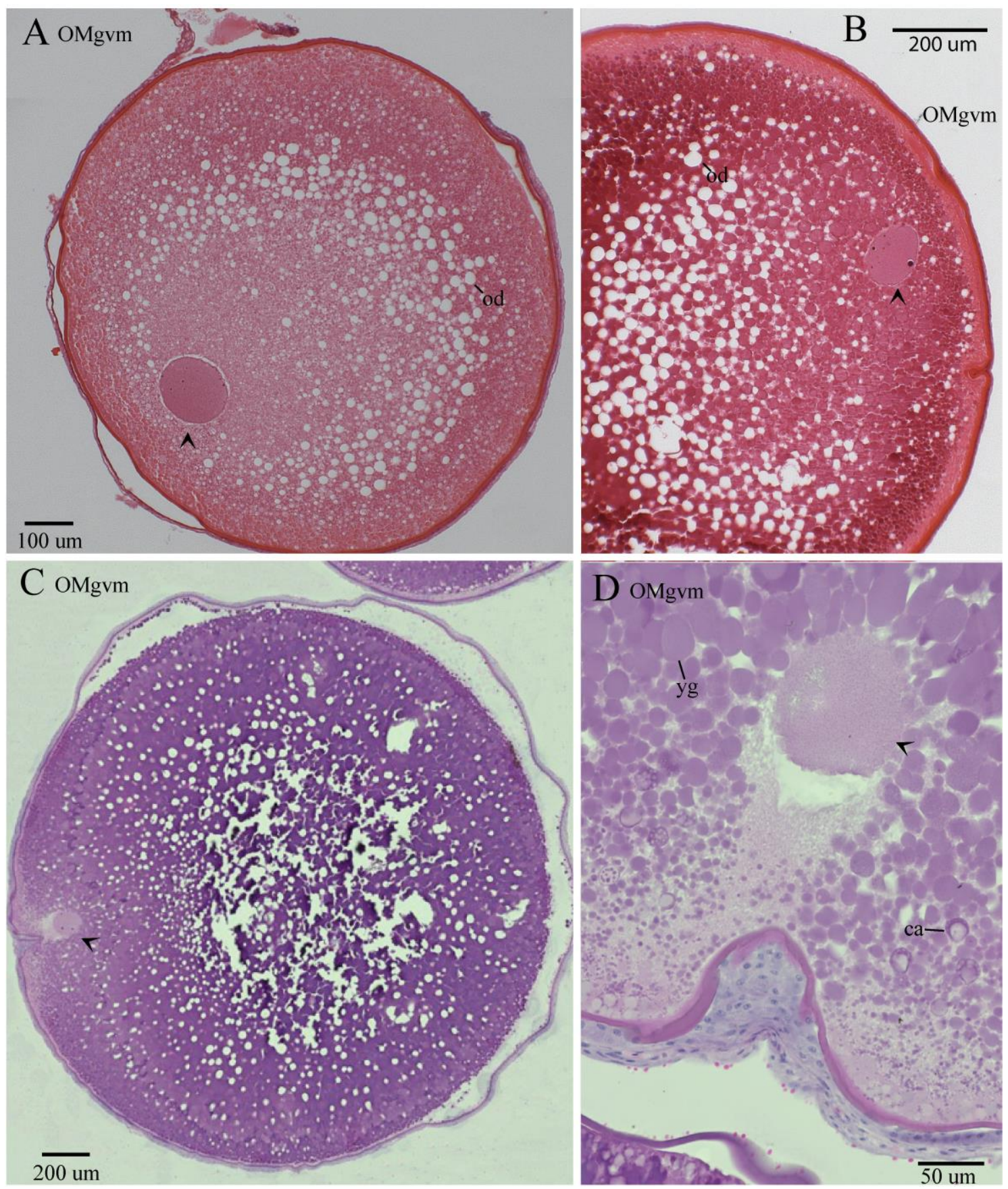

Figure 5. Light micrographs of oocyte maturation (OM) step in Arapaima gigas. (A) Early

migration of germinal vesicle towards the animal pole, depicting oil droplets coalescing.



a reduced nucleo-cytoplasmic ratio. Hematoxylin - eosin, Bar=200 $\mu$ m. (C) Germinal vesicle

634 close to micropyle area at the maximum hydration volume observed prior to germinal vesicle

635 breakdown. Hematoxylin - eosin, Bar=200 $\mu$ m. (D) Magnification of the peripheric area of a

636 OMgvm oocyte depicting the migrated germinal vesicle close to the micropyle area. 
637 Hematoxylin - eosin, Bar $=50 \mu \mathrm{m}$. Arrow $=$ germinal vesicle, od $=$ oil droplet, $y g=$ yolk 638 granules, $\mathrm{ca}=$ cortical alveoli.

639

640

641

642

643

644

645

646

647

648

649

650

651

652

653

654

655

656

657

658

659

660

661

662

663 

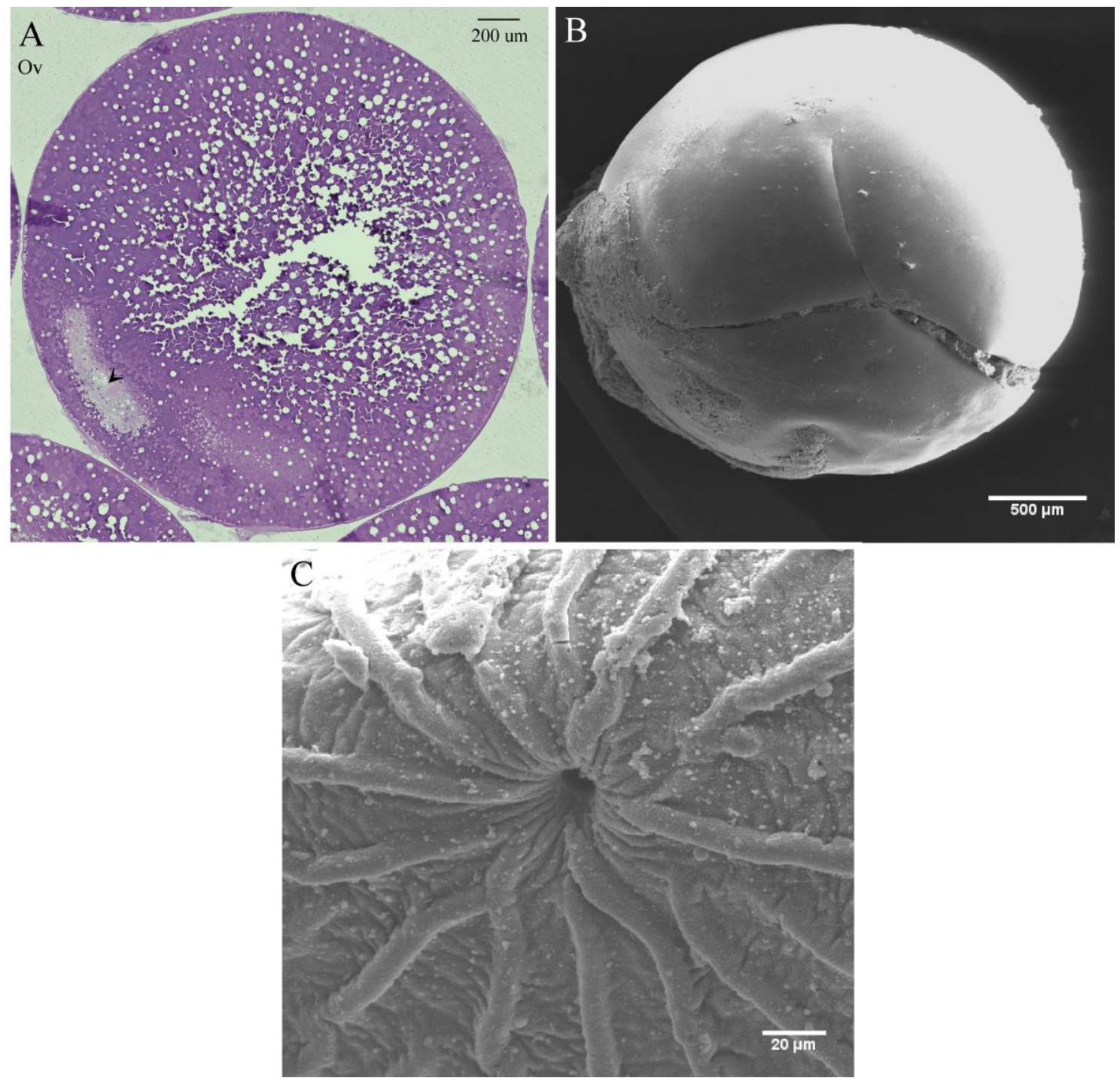

665 Figure 6. Non-fertilized eggs of Arapaima gigas at the post-ovulatory step (OV). (A). Light micrograph depicting region where germinal vesicle broke down (arrow). Hematoxylin - eosin.

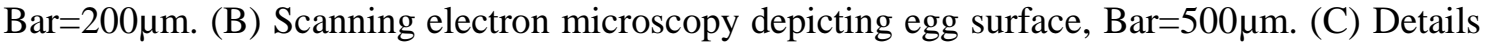
of the concentric ridges external to themicropyle. $\mathrm{Bar}=20 \mu \mathrm{m}$.

669

670

671

672

673

674

675 


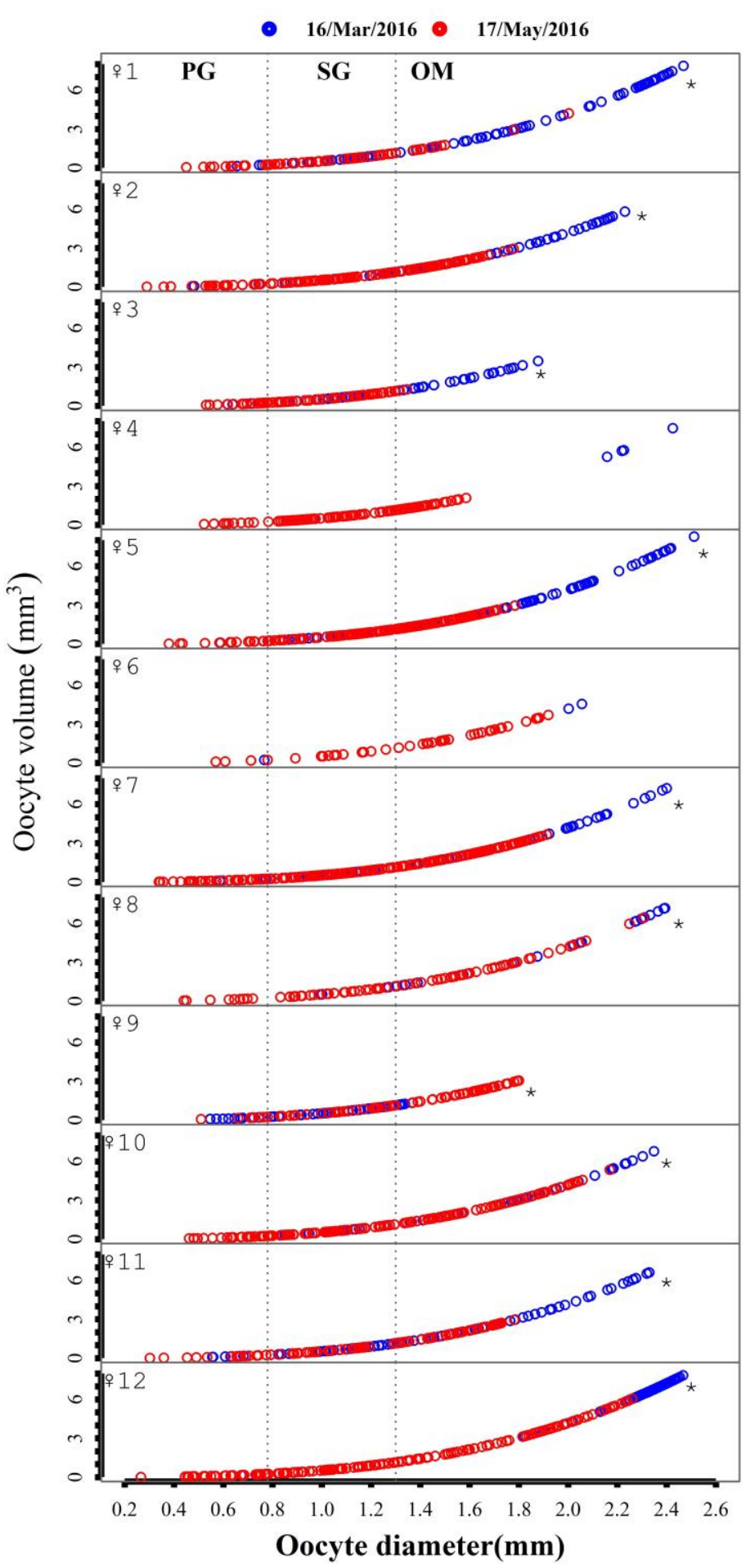

Oocyte diameter(mm)

677 Figure 7. Oocyte diameter $(\mathrm{mm})$ vs volume $\left(\mathrm{mm}^{3}\right)$ for 12 adult females of Arapaima gigas 678 sampled on $16^{\text {th }}$ March (blue) and $17^{\text {th }}$ May (red) 2016. Dashed line indicates stage of oocyte 679 development for a given oocyte diameter range $(\mathrm{PG}=$ primary growth; $\mathrm{SG}=$ secondary growth 680 and $\mathrm{OM}=$ oocyte maturation). * indicate significant difference in the leading cohort between 681 different sampling dates. 

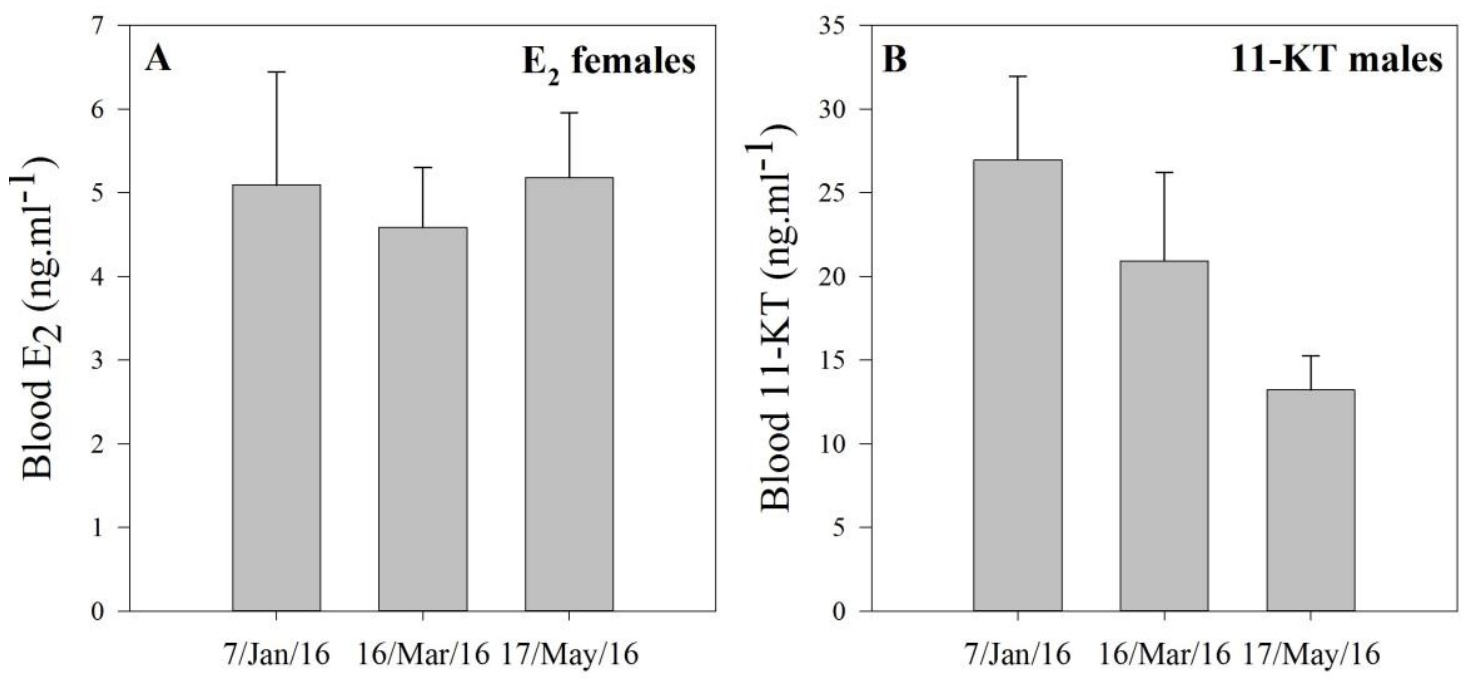

682

683

684

685

686

687

688

689

690

691

692

693

694

695

696

697

698

699

700

701

Figure 8. Plasma sex steroid levels in Arapaima gigas broodstock. No significant time effects were seen $(\mathrm{P}>0.05)$. (A) 17ß-oestradiol $\left(\mathrm{E}_{2}\right)$ in females (12 individuals). (B) 11-ketotestosterone (11-KT) in males (12 individuals).

\section{.}

7

88

(1)




\begin{tabular}{|c|c|c|c|c|c|c|c|}
\hline Juvenile $^{\circ}$ & Body Weight & Total Length $(\mathrm{cm})$ & Procedure time (min) & Gender & Leading Cohort & Leaging Cohort Stage & Ovary Stage * \\
\hline 1 & 12.1 & 110.5 & 4.0 & Female & 220.9 & PGpn & $\mathrm{I}$ \\
\hline 2 & 9.5 & 107.0 & 2.6 & Female & 161.9 & PGpn & $\mathrm{I}$ \\
\hline 3 & 10.2 & 107.2 & 1.6 & Female & 159.1 & PGpn & I \\
\hline 4 & 12.2 & 100.0 & 0.3 & Female & 208.9 & PGpn & I \\
\hline 5 & 10.1 & 107.0 & - & Male & - & - & - \\
\hline 6 & 8.9 & 106.0 & - & Male & - & - & - \\
\hline 7 & 10.2 & 107.5 & - & Male & - & - & - \\
\hline 8 & 11.7 & 112.5 & $1: 6$ & Female & 215.4 & PGpn & I \\
\hline 9 & 9.8 & 106.0 & 1.1 & Female & 191.2 & PGpn & I \\
\hline 10 & 11.6 & 115.0 & 7.1 & Female & 167.4 & PGpn & I \\
\hline 11 & 10.6 & 109.5 & - & Male & - & - & - \\
\hline 12 & 9.9 & 107.7 & - & Male & - & - & - \\
\hline 13 & 9.8 & 106.0 & No access & Female & 209.2 & PGpn & I \\
\hline 14 & 10.9 & 112.0 & - & Male & - & - & - \\
\hline 15 & 8.9 & 101.5 & 9.0 & Female & 206.1 & PGpn & I \\
\hline 16 & 9.6 & 103.0 & - & Male & - & - & - \\
\hline 17 & 11.3 & 110.0 & 0.7 & Female & 220.1 & PGpn & I \\
\hline 18 & 9.6 & 98.5 & 2.3 & Female & 246.5 & PGpn & I \\
\hline 19 & 10.4 & 110.5 & 1.9 & Female & 229.5 & PGpn & I \\
\hline 20 & 8.0 & 98.5 & No access & Female & 170.3 & PGpn & I \\
\hline
\end{tabular}




\begin{tabular}{|c|c|c|c|c|c|c|c|}
\hline Adult female $n^{\circ}$ & Body Weight (kg) & Total Length (cm) & Procedure time (min) & Ovary color & $\begin{array}{l}\text { Leading Cohort } \\
\qquad(\mu \mathrm{m})\end{array}$ & $\begin{array}{c}\text { Leading } \\
\text { Cohort Stage }\end{array}$ & Ovary Stage * \\
\hline 1 & 37.0 & 155.0 & 1.3 & green & 2391.5 & OMgvm & IV \\
\hline 2 & 31.0 & 156.0 & 0.7 & green & 2152.5 & OMgvm & IV \\
\hline 3 & 45.0 & 162.0 & 1.2 & green & 1740.9 & OMgvm & IV \\
\hline 4 & - & - & 0.6 & green & 2256.4 & OMgvm & IV \\
\hline 5 & 48.5 & 175.0 & 0.7 & green & 2399.5 & OMgvm & IV \\
\hline 6 & 41.0 & 167.0 & 0.6 & green & 2064.5 & OMgvm & IV \\
\hline 7 & 48.0 & 173.0 & 0.5 & green & 2232.6 & OMgvm & IV \\
\hline 8 & 51.0 & 175.0 & 0.7 & green & 2299.1 & OMgvm & IV \\
\hline 9 & 41.0 & 160.0 & 5.8 & yellow & 1324.0 & SGfg & II \\
\hline 10 & 45.0 & 168.0 & 2.1 & green & 2225.1 & OMgvm & IV \\
\hline 11 & 42.0 & 166.0 & 0.5 & green & 2258.0 & OMgvm & IV \\
\hline 12 & 44.0 & 171.0 & 0.3 & green & 2435.4 & OV & IV \\
\hline
\end{tabular}

